\title{
Dialogic Reading untuk Mengembangkan Pemahaman Empati Anak Usia 3-4 Tahun
}

\author{
Korifanny Petrisia ${ }^{1}$, Rose Mini Agoes Salim², Luh Surini Yulia Savitri ${ }^{3}$ \\ ${ }^{1,2,3}$ Program Studi Psikologi Terapan, Peminatan Psikologi Anak Usia Dini \\ Fakultas Psikologi, Universitas Indonesia \\ e-mail: ${ }^{1}$ hellokorfan@gmail.com, ${ }^{2}$ romy.prianto@gmail.com, ${ }^{3}$ lsy.savitri@gmail.com
}

\begin{abstract}
Abstrak. Meningkatnya jumlah anak-anak sebagai pelaku beberapa tindak kejahatan memperlihatkan bahwa anak membutuhkan empati sebagai penyangga perilaku. Pemahaman empati akan membantu anak memahami apa yang dirasakan oleh orang lain sehingga akan peka saat melakukan sebuah perilaku. Penelitian ini bertujuan untuk melihat efektivitas dialogic reading untuk mengembangkan pemahaman empati anak usia 3-4 tahun. Alat ukur yang digunakan dalam penelitian ini adalah Empathy Scale for Children (ESC). Disain penelitian ini adalah one group pre-test-post-test design. Dialogic reading merupakan metode pembacaan cerita interaktif dengan tanya jawab antara pembaca cerita dengan anak. Penelitian ini menggunakan 4 buku cerita bergambar yang bercerita mengenai perasaan senang, sedih, marah dan takut. Dialogic reading dilakukan selama 4 hari pada TK XY, Kota Payakumbuh, Sumatera Barat dengan total partisipan sebanyak 29. Analisis hasil penelitian menunjukkan bahwa dialogic reading secara signifikan meningkatkan pemahaman empati anak usia 3-4 tahun. Untuk penelitian selanjutnya, dapat melakukan checklist perilaku sebelum dan sesudah intervensi atau melakukan dialogic reading secara individu dengan orang tua atau guru.
\end{abstract}

Kata kunci: Empati, pembacaaan buku cerita, buku cerita bergambar, dialogic reading

Abstract. The increasing number of children as offenders shows that children need empathy as buffer for their behavior. Empathy understanding will help children to have perspectives of what other people feel, hence children will have some consideration before act. The aim of this research is to test the effectiveness dialogic reading to develop empathy understanding of children age 3-4 years old. The effectiveness of dialogic reading is measured using Empathy Scale for Children (ESC). The Research design is one group pre-test-post-test design. This research using dialogic reading, which is interactive reading method between the storyteller and children. The dialogic reading uses 4 picture storybooks each about happy, sad, anger and scare that conducted for 4 days at XY Kindergarten, Payakumbuh, West Sumatra. The statistical results demonstrate that there is significant difference at children's empathy understanding score before and after the dialogic reading. For further research, can do the behavior checklist before and after the intervention or do one to one book reading with teacher or parent.

Keyword: Empathy, book reading, picture storybook, dialogic reading

Pada tahun 2014 Komisi Perlindungan Anak Indonesia ("KPAI") menyatakan bahwa terjadi pergeseran perilaku kejahatan yang tidak hanya dilakukan oleh orang dewasa melainkan anak-anak dengan rentang usia 6-14 tahun (Tempo, 31 Desember 2014). 
Sejalan dengan hal ini Pusat Data Anak Berhadapan dengan Hukum Komnas melaporkan ada sekitar 2.879 anak melakukan tindak kekerasan dan harus berhadapan dengan hukum, $9 \%$ diantaranya adalah anak dengan rentang usia 6-12 tahun (Liputan 6, 31 Desember 2014). Penelitian Arsenio (2005 dalam Malti \& Krettenauer, 2013) menyebutkan bahwa moral membantu anak untuk menghindari perilaku antisosial seperti yang ada diatas. Perilaku antisosial adalah perilaku yang secara sadar dilakukan oleh anak dan dapat menyebabkan kerusakan fisik atau penderitaan bagi orang lain (Colasante, 2013). Perilaku antisosial atau perilaku agresif yang sudah terlihat ketika usia dini seperti bullying, mencuri, dan melanggar peraturan (Eidsvaag, 2012; Maughan et, al., 2004). Moral merupakan kemampuan untuk membedakan baik dan buruk, sehingga seseorang dapat berperilaku sesuai dengan keadaan yang dihadapinya (Hoffman, 2000). Empati ditetapkan sebagai salah satu aspek penting dari moral dan aspek penting dalam kehidupan manusia (Goleman, 1995). Hoffman (2000) menyatakan bahwa empati membantu menciptakan masyarakat yang damai.

Hoffman (2000) menyatakan bahwa empati adalah respon afeksi yang ditujukan pada orang lain dengan terlebih dahulu menyesuaikan dengan keadaan yang dialami orang lain tersebut. Decety dan Moriguchi (2007) menjelaskan empati sebagai kemampuan untuk merekognisi, memahami dan memberikan respon yang sesuai dengan apa yang dirasakan oleh orang lain. Empati terbentuk dari dua komponen yaitu empati kognitif (cognitive empathy) dan empati afektif (affective empathy).Empati berkembang dari melihat setiap situasi berdasarkan sudut pandang orang yang mengalami (kognitif) dan kemudian timbul afeksi atau rasa peduli pada orang tersebut (Prianto, 2006). Kognitif empati merujuk kepada kemampuan untuk memahami situasi serta mengenali emosi dan merefleksikan apa yang dirasakan orang lain (Volbrecht, Lemery-Chalfant, Aksan, ZahnWaxier, \& Goldsmith, 2007) dan afektif empati adalah reaksi yang terjadi dalam diri individu sebagai hasil dari pengamatan keadaan emosi orang lain (Losoya \& Eisenberg, 2001). Afektif empati dapat terwujud ketika seseorang telah dapat mengenali dan memahami apa yang dialami oleh orang lain sehingga ia dapat merasakan perasaan yang sama/ mirip dengan yang dialami orang tersebut dan memberikan respon yang tepat (Eisenberg, Fabes, \& Spinrad, 2006). Integrasi antara kognitif dan afektif empati akan melahirkan empati dalam bentuk perilaku (Vreeke \& van der Mark, 2003).

Empati berkembang sejak anak dilahirkan, perilaku bayi yang ikut menangis saat mendengar bayi lain menangis merupakan bentuk empati paling sederhana dan dilakukan secara spontan, kemudian empati terus berkembang dengan pertambahan usia anak (Roth-Hanania, Davidov, \& Zahn-Waxler, 2011; Kahraman \& Akgun, 2008 dalam Akyol, 2014). Hoffman (2000) menjelaskan bahwa perkembangan empati dimulai pada usia 2-3 tahun dan pada usia ini pula anak mulai mengalami perubahan lingkungan yang dinamis (Knafo, 2008). Pada usia 2 tahun, anak mulai dapat membedakan dirinya dan orang lain dan kemampuan perspective taking mulai berkembang pada usia 3 tahun yang merupakan dasar untuk memiliki empati. Seiring dengan perkembangan kognitif, kemampuan empati berkembang sejalan dengan peningkatan pengetahuan emosi yang beragam yang diketahui dan dirasakan oleh anak (Dadds, Hunter, Hawes, Frost, Vassallo, \&Masry, 2008). Perkembangan pesat empati terjadi antara usia 3-5 tahun (Venesky, 2013). Berdasarkan teori perkembangan kognisi Piaget, kognitif empati mulai muncul 
pada usia anak antara 3-5 tahun (Hinnant, 2005) dan berada pada tahap preoperational yaitu kemampuan penalaran anak sudah dapat memahami bahwa orang lain bisa merasakan hal yang berbeda dari yang mereka rasakan (Papalia, 2014). Oleh karena itu usia 3-4 tahun sesuai untuk diberikan program untuk mengembangkan pemahaman empati anak, sehingga dapat menjadi stimulasi bagi pemahaman empati anak.

Empati dipengaruhi oleh faktor genetik dan faktor lingkungan (McDonald \& Messinger, 2011; Knafo \& Plomin, 2006b). Faktor lingkungan memegang peranan lebih besar dalam perkembangan empati seseorang (Knafo et al, 2008). Faktor lingkungan yang mempengaruhi perkembangan empati diawali dari keluarga, penelitian menemukan bahwa orang tua merupakan pembentuk empati pada anak (Cornell \& Frick, 2007). Hubungan antara orang tua dan anak dapat membantu mengembangkan dan mendidik empati anak (Gordon, 2009). Selain keluarga, salah satu faktor lingkungan yang dapat membantu mengembangkan empati adalah lingkungan sekolah. Lingkungan sekolah yang memberikan contoh perilaku peka dan penuh perhatian dalam kehidupan sehari-hari yang didapatkan dari aparat sekolah dan teman-teman (Thompson \& Gullone, 2003). Sekolah dapat menjadi salah satu tempat untuk mengembangkan empati dengan menyediakan program-program pengembangan empati atau mengajak orang tua untuk mengembangkan program yang ada dalam lingkungan keluarga (Stetson, Hurley, \& Miller, 2003). Program-program pengembangan empati yang ada di sekolah dapat dilanjutkan di rumah dengan kerjasama dari orang tua. Oleh karena itu sekolah membutuhkan program untuk mengembangkan pemahaman empati anak yang efektif.

Beberapa metode yang umumnya dilakukan dalam program untuk mengembangkan empati di lingkungan sekolah adalah melalui puisi (Xerri \& Agius, 2015), pemeliharan binatang (Daly \& Morton, 2006; Daly \& Suggs, 2010), video (Howe et al., 2008), dan buku (Zembylas, 2013; Upright, 2002). Penggunaan buku menjadi salah satu metode yang paling sering digunakan untuk mengembangkan empati pada anak. Buku merupakan media edukasi yang membantu mengembangkan pemahaman mengenai lingkungan sekitar dan nilai-nilai sosial (Puurtinen, 1998 dalam Isitan, 2016). Dengan membacakan buku mengenai empati, anak akan belajar bagaimana cara hidup dengan mengamalkan empati tersebut dan mendapatkan pemahaman yang lebih dalam mengenai empati itu sendiri (Narvaes, 2002). Narasi pada buku mengajak anak untuk mempraktekkan bagaimana melihat sebuah keadaan dari sudut pandang orang lain (perspective taking), mencontohkan perilaku-perilaku prososial dan mengembangkan empati (Shanty, 2016; Narvaes, 2002). Buku menjadi media anak untuk belajar mengenai hubungan antara sebuah situasi dan respon afeksi yang diberikan (Karniol, 2012).

Anak usia 3-4 tahun membutuhkan arahan dari orang dewasa dalam membaca buku, sehingga metode pembacaan cerita oleh orang dewasa pada anak merupakan cara yang dianggap paling efektif (Upright, 2002). Dialogic reading merupakan salah satu metode pembacaan buku yang dinilai efektif untuk menyampaikan isi dari buku, khususnya untuk pembelajaran sosial, emosi dan moral (Shanty, 2016). Dialogic reading merupakan metode pembacaan yang bertujuan mengajak anak untuk berpartisipasi aktif selama pembacaan cerita, dengan mengajak anak untuk melengkapi kalimat yang disampaikan oleh pembaca cerita, mengidentifikasi objek pada buku atau menghubungkan hal-hal 
yang ada dalam cerita dengan pengalaman anak (Ewers \& Brownson, 1999). Dialogic reading menyediakan struktur sederhana pembacaan cerita antara orang tua/ guru dan anak agar efektif dan produktif (Lane \& Wright, 2007). Orang dewasa sebagai pembaca cerita dapat menjadi pemandu untuk membantu anak memahami konten buku dengan memberikan pertanyaan terbuka atau menanyakan apa yang akan terjadi, mengingat kembali bagian-bagian cerita di buku, serta mendorong anak untuk mengulang respon yang mereka berikan (Pillinger \& Wood, 2014). Dialogic reading membuat proses membaca buku menjadi lebih interaktif, dipandu oleh orang dewasa yang aktif, scaffolding antara anak dan orang dewasa dalam pengulangan pembacaan buku, individu atau kelompok kecil yang berisi 5-8 orang, dan strategi pertanyaan saat dan setelah pembacaan buku (Doyle \& Bramwell, 2006). Proses pembacaan yang interaktif pada dialogic reading akan membantu anak usia 2-3 tahun atau yang lebih tua memahami konten dari buku yang dibacakan dengan lebih baik (Mol, Bus, de Jong, \& Smeets, 2008). Dialogic reading menggunakann buku cerita bergambar untuk membangun pembacaan cerita yang interaktif (Flynn, 2011). Penggunaan buku cerita bergambar adalah agar anak dapat memahami cerita melalui gambar jika belum bisa membaca, sehigga tidak menyulitkan anak untuk berpartisipasi dalam proses pembacaan cerita (Marriot, 1998 dalam Al-Somadi, 2012). Buku cerita bergambar (picture storybook) merupakan jenis literatur yang spesial untuk anak usia prasekolah, kombinasi gambar dan teks yang seimbang dan dibacakan dengan didampingi oleh orang yang lebih tua bagi anak yang belum dapat membaca (Al-Somadi, 2012; Catalano, 2005). Oleh karena itu penelitian ini akan melihat efektivitas dialogic reading untuk mengembangkan pemahaman empati pada anak usia 3-4 tahun.

Decety dan Moriguchi (2007) menjelaskan empati sebagai kemampuan untuk merekognisi, memahami dan memberikan respon yang sesuai dengan apa yang dirasakan oleh orang lain. McInnis (2014) menyatakan bahwa empati adalah kemampuan untuk mengidentifikasi emosi apa yang dirasakan oleh orang lain dan memberikan respon yang sesuai dengan emosi yang dirasakan oleh orang lain. Defini empati yang digunakan dalam penelitian ini adalah kemampuan seseorang untuk dapat mengidentifikasi emosi yang dirasakan oleh orang lain. Empati terbentuk dari kemampuan seseorang untuk memahami apa yang dirasakan oleh orang lain dan kemampuan untuk dapat merasakan sendiri apa yang dirasakan orang lain tersebut yang dan kemudian memberikan respon yang sesuai dengan keadaan tersebut (Jefferies, A. M., 2005). Blair (2005) menjelaskan komponen pembentuk empati yaitu empati kognitif (cognitive empathy) dan empati afektif (affective empathy). Penelitian menyebutkan bahwa empati kognitif merupakan tahapan awal dari perkembangan empati afektif dan kedua komponen ini saling berkaitan (Batson, Fultz, \& Schoenrade, 1987; Feshbach, 1987 dalam McInnis, 2014; Eisenberg et al., 2006) untuk menghasilkan perilaku empati (Hoffman, 2000). Secara garis besar, kognitif empati terbatas pada kemampuan menginterpretasikan apa yang terlihat secara fisik dari emosi seseorang sedangkan afektif empati adalah ikut merasakan apa yang dirasakan oleh orang lain (McInnis, 2014; Prianto, 2006).

Sesuai dengan perkembangan kognitif anak, usia 3-4 tahun masuk dalam tahap veridical empathic distress menurut kategori yang ditetapkan oleh Hoffman (2000), yaitu anak mulai menyadari bahwa apa yang dirasakan orang lain bisa berbeda dari apa yang mereka 
rasakan (McInnis, 2014). Dege (2008 dalam McInnis, 2014) menyatakan bahwa tahap ini merupakan landasan untuk mengembangkan pemahaman empati anak, seiring berkembangnya kemampuan anak mengidentifikasi emosi dan bahasa. Borba (2001) menjelaskan tahapan awal untuk mengembangkan empati anak adalah mengembangkan pengetahuan dan kosa kata emosi yang dimiliki anak. Kendala yang umumnya dialami anak untuk mengembangkan kemampuan empati mereka adalah ketidakmampuan anak untuk mengidentifikasi dan mengekspresikan emosi yang mereka hadapi. Anak kesulitian merasakan apa yang dirasakan oleh orang lain karena mereka tidak mengenali apa emosi yang dirasakan oleh orang lain. Oleh karena itu, anak membutuhkan panduan dari orang tua/ guru untuk mengenali nama-nama emosi dan membiasakan diri menggunakan nama emosi untuk mengekspresikan apa yang mereka rasakan. Ketika anak telah mengenali apa nama emosi yang mereka rasakan, pemahaman empati anak akan berkembang karena mereka akan mengenali apa yang dirasakan oleh orang lain.

Buku merupakan media yang sesuai untuk anak usia 2-6 tahun untuk mengenalkan anak mengenai hal-hal yang ada di sekitarnya (Karniol, 2012) dan sebagian besar dari anak usia dini menunjukkan ketertarikan pada buku (Wang, 2014). Buku merupakan salah satu media yang umum diperkenalkan sejak dini oleh orang tua kepada anak. Buku cerita dapat membantu anak memahami suatu kondisi dari perspektif orang lain dengan cara yang nyaman dan tidak menakutkan (Lamme, Krogh, dan Yachmetz, 1992 dalam Widiana, 2012). Perkembangan yang terjadi pada usia ini membuat anak memiliki banyak imajinasi dan kreativitas untuk menginterpretasikan cerita dan menghubungkan dengan kehidupan mereka sehari-hari (Al-Somadi, 2012).

Dialogic reading menjadi metode pembacaan yang sesuai untuk memenuhi keterbatasan literasi anak usia 3-4 tahun. Dialogic reading merupakan metode pembacaan paling umum digunakan dan efektif untuk anak usia 2-3 tahun atau yang lebih tua (Mol, 2008; Lane \& Wright, 2007). Doyle dan Bramwell (2006) menyatakan bahwa metode ini cocok digunakan untuk mengembangkan pemahaman empati anak. Dialogic reading merupakan metode pembacaan cerita interaktif dengan menggunakan buku cerita bergambar (Arnold \& Whitehurst, 1994). Metode ini mendorong anak untuk menjadi pembaca cerita (storyteller) dan orang dewasa sebagai pendengar (active listener) yang memberikan semua bantuan yang dibutuhkan anak dan memberikan respon terhadap semua pernyataan dan pertanyaan anak (Wang, 2014; Blom-Hoffman, O'Neil-Pirozzi, \& Cutting, 2006).Keutamaan dari dialogic reading adalah pemahaman yang lebih baik terhadap isi bacaan dan juga memberikan pengalaman kepada anak untuk belajar disiplin dan bergantian dalam berbicara atau mendengarkan orang lain berbicara, sehingga juga mengasah kemampuan sosial anak (Doyle \& Bramwell, 2006). Dialogic reading memiliki 3 prinsip dasar yaitu, mengajak anak untuk menjadi active learner selama proses membaca buku, memberikan umpan balik yang dapat menambah pengetahuan anak, dan menantang pengetahuan dan kemampuan anak dengan memberikan tingkat kompleksitas percakapan diatas kemampuan anak (Pillinger \& Wood, 2014; De Temple \& Snow, 2003). Dialogic reading sesuai digunakan untuk membacakan buku bergambar, ilustrasi dari buku cerita bergambar menjadi fokus dari diskusi dan interaksi yang dibangun oleh orang dewasa dan anak. Jalongo (2004) menyatakan bahwa buku cerita bergambar sesuai dengan kemampuan anak usia 3-4 tahun. Buku bergambar dianggap 
sesuai untuk anak usia 3-4 tahun, kehadiran gambar melengkapi kemampuan anak yang sebagian besar belum dapat membaca, sehingga anak dapat belajar memahami melalui gambar (Marriot, 1998 dalam Al-Somadi, 2012).

\section{METODE}

Penelitian ini merupakan penelitian kuantitatif, yang mana jumlah skor yang didapatkan dan dianalisa merupakan hasil dari perhitungan statistik dari alat ukur yang digunakan. Disain penelitian menggunakan one group pre-test post-test design, yaitu dilakukan pengukuran kepada kelompok subjek terlebih dahulu (pretest), kemudian diberikan perlakukan atau intervensi tertentu, setelah diberikan intervensi, dilakukan pengukuran kembali terhadap kelompok subjek tersebut (post-test). Partisipan dalam penelitian ini adalah anak yang berusia 3-4 tahun, tidak berkebutuhan khusus, dan anak bersekolah di sekolah yang belum memiliki atau melakukan program pengembangan empati. Partisipan dipilih dengan teknik purposive sampling, yaitu sampel diambil berdasarkan pertimbangan dari peneliti untuk menetapkan sampel yang dianggap sesuai dengan karakteristik, tujuan dari penelitian, dan membutuhkan program pengembangan empati serta bersedia memberikan informasi yang dibutuhkan (Kumar, 2011).

Alat ukur dalam penelitian ini adalah Empathy Scale for Children (ESC) yang dikembangkan oleh Akyol dan Durmus (2010) untuk anak usia prasekolah. ESC terdiri dari gambar-gambar yang berisi cerita singkat mengenai situasi yang menibulkan emosi senang, sedih, marah dan takut dalam kehidupan sehari-hari anak usia dini. ESC terdiri dari dua belas gambar dengan cerita singkat dan 8 gambar ekspresi ekspresi wajah mengenai emosi senang, sedih, marah dan takut dengan format gambar hitam putih. 12 gambar dengan cerita singkat masing-masing berisi 3 cerita bergambar untuk setiap emosi. Gambar dilengkapi dengan cerita singkat akan diakhiri dengan pertanyaan kepada anak mengenai apa yang dirasakan tokoh dalam gambar tersebut. 8 gambar ekspresi ini berisi empat gambar ekspresi perempuan (ekspresi wajah saja) dan empat gambar ekspresi laki-laki (ekspresi wajah saja) yaitu senang, sedih, marah dan takut. 8 gambar ekspresi ditampilkan sesuai dengan jenis kelamin anak yang akan diuji. Peneliti melakuka beberapa kali uji coba sebelum menggunakan alat ukur ini, berdasarkan hasil uji coba ini peneliti melakukan beberapa perubahan pada alat ukur. Perubahan-perubahan tersebut adalah mengubah teks dari Bahasa Inggris menjadi Bahasa Indonesia, memberikan warna pada cerita bergambar karena hal ini lebih menarik bagi anak, mengurangi jumlah cerita bergambar menjadi 8 dan menggunakan gambar ekspresi hanya pada awal pertemuan setiapa anak sebagai pengenalan nama emosi. Peneliti juga melakukan perubahan pada skor, yang awalnya memiliki skor 0 dan 1 menjadi 0,1 , dan 2. Hal ini dilakukan sesuai dengan temuan yang didapat dari hasil uji coba, beberapa anak hanya mengetahui ekspresi yang timbul akan tetapi belum mengetahui nama emosi yang tepat. Skor yang digunakan pada alat ukur ini menggunakan skala tipe Likert, dengan skala skor yaitu 0,1 , dan 2. Skor 0 diberikan jika anak tidak dapat memberikan jawaban setelah dua kali pengulangan cerita dan pertanyaan. Skor 1 diberikan jika anak memberikan jawaban ekspresi yang muncul dari perasaan yang tepat (misal emosi senang disampaikan dengan kata ketawa, emosi takut disampaikan dengan lari). Skor 2 diberikan 
jika menyebutkan nama emosi dengan tepat. Oleh karena itu, skor tertinggi berjumlah 16 dan skor terendah adalah 0 .

Seluruh buku cerita yang digunakan dalam penelitian ini merupakan buku yang peneliti rancang untuk penelitian ini. Peneliti bertindak sebagai pembuat naskah dan pembuatan gambar dibantu oleh ilustrator. Penelitian ini menggunakan 4 buku cerita bergambar yang bercerita mengenai 4 emosi, yaitu emosi senang, sedih, marah dan takut. Cerita disusun untuk mengenalkan anak pada empat emosi yaitu senang, sedih, marah, dan takut. Cerita dibuat dengan alur yang sederhana, berurut dan berlatar belakang kejadiankejadian yang dekat dengan anak usia 3-4 tahun. Kalimat-kalimat pendek dan sederhana yang menjelaskan hal-hal yang terkait dengan emosi serta beberapa kejadian yang menjadi latar belakang sebuah emosi timbul. Tokoh dalam buku ini adalah manusia, yaitu dengan tokoh utama seorang anak laki-laki bernama Tom dan anak perempuan bernama Rosi. Setiap buku cerita menceritakan pengalaman yang dialami Tom dan Rosi dalam situasi yang berbeda. Penyusunan cerita dalam buku ini didasarkan pada metode dialogic reading, dimana pada buku cerita terdapat pertanyaan-pertanyaan yang digunakan sebagai panduan pembaca cerita untuk mendorong partisipasi anak untuk terlibat aktif dalam pembacaan buku.
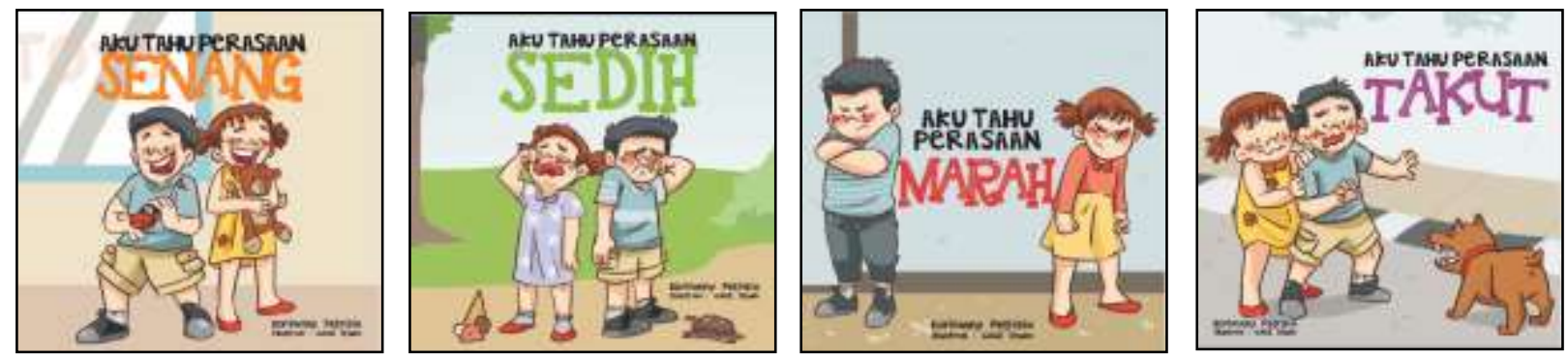

Gambar 1. Sampul buku cerita bergambar

Pengumpulan data dilakukan dengan pre-test dan post-test pada masing-masing partisipan. Tes pada anak dilakukan sebelum dan sesudah intervensi menggunakan alat ukur yang telah disiapkan, yaitu anak menjawab apa yang dirasakan tokoh yang ada di dalam cerita dengan jawaban senang, sedih, marah atau takut. Pre-test dan post-test dilakukan secara individu pada ruangan yang terpisah dari ruang kelasnya. Pre-test dan post-test direncanakan dilakukan pada 30 partisipan, akan tetapi sesaat sebelum pre-test partisipan diketahui sakit dan harus dipulangkan. Partisipan yang digunakan hingga akhir penelitian ini menjadi 29 partisipan. Pre-test dan post-test masing-masing dilakukan selama 1 hari. Intervensi berupa pembacaan cerita dengan dialogic reading dilakukan selama 4 hari dengan pembacaan 1 buku setiap hari. Pembacaan cerita dilakukan dalam kelompok kecil, yang berisi 5-6 orang per kelompok dengan satu orang pembaca cerita. Selama dan sesudah pembacaan buku ini, pembaca cerita memberikan pertanyaanpertanyaan untuk mendorong partisipasi partisipan. Metode analisis data yang digunakan untuk mengukur sampel yang sama secara berulang adalah the wilcoxon signed-rank test (Gravetter \& Forzano, 2009). The wilcoxon signed-rank test merupakan analisis data non-parametrik yang menguji beda antara pre-test dan post-test. 


\section{HASIL}

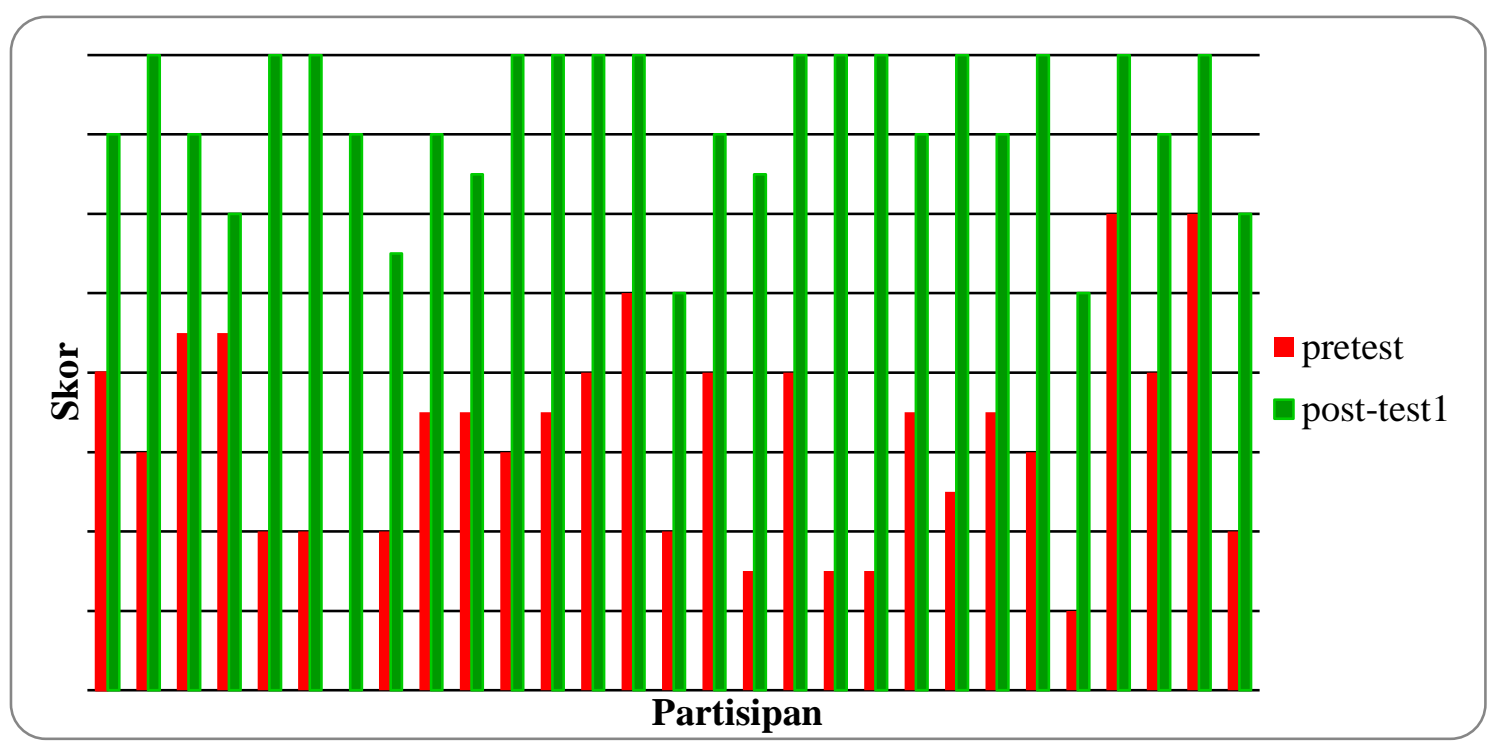

Gambar 2. Skor nilai pre-test dan post-test

Berdasarkan data di atas dinyatakan bahwa skor terendah pada pre-test adalah 0 dan skor tertinggi adalah 12 . Hasil skor pada post-test 1 menunjukkan peningkatan skor pada semua partisipan setelah intervensi dilakukan. Nilai skor terendah pada post-test 1 adalah 10 dan skor tertinggi adalah 16, yang merupakan nilai maksimal pada alat ukur ini. Terdapat 14 partisipan yang mendapatkan nilai maksimal pada post-test 1 .

Tabel 1.

Hasil analisis statistik nilai rata-rata pre-test dan post-test

\begin{tabular}{lccccccc}
\hline & $N$ & Mean & $\begin{array}{c}\text { Std } \\
\text { Deviation }\end{array}$ & Minimum & Maximum & $\begin{array}{c}Z \\
\text { Value }\end{array}$ & $p$ \\
\hline Pre-test & 29 & 6.2413 & 2.861757 & 0.00 & 12.00 & $-4.712^{\mathrm{b}}$ & .000 \\
Post-test & 29 & 14.3793 & 1.916354 & 10.00 & 16.00 & & \\
\hline
\end{tabular}

Empathy Scale for Children menggunakan skor terendah yang adalah 0 dan tertinggi adalah 16. Dari tabel 4.1, nilai rata-rata (mean) post-test lebih besar daripada nilai ratarata pre-test. Nilai $Z$ adalah $-4,712$ dengan $\mathrm{p}=0.000(\mathrm{p}<0,05)$, dengan nilai signifakansi $\mathrm{p}<0,05$, hal ini menunjukkan adanya perbedaan nilai rata-rata yang signifikan antara pre-test dan post-test. Hal itu menunjukkan terdapat peningkatan skor pemahaman empati anak antara sebelum dan sesudah mengikuti program pembacaan buku cerita dengan dialogic reading. Hasil ini memperlihatkan bahwa pembacaan buku cerita bergambar dengan dialogic reading efektif meningkatkan pemahaman empati anak.

Hasil observasi menunjukkan bahwa dialogic reading memberikan dampak positif kepada partisipan dari hari ke hari. Pada hari pertama, banyak partisipan yang masih sulit 
untuk barpartisipasi aktif dalam kegiatan pembacaan buku, bahkan ada partisipan yang tidak mau mengeluarkan suara untuk turut berpartisipasi. Kegiatan yang dilakukan dalam kelompok dan pembaca cerita yang mendorong anak untuk berpartisipasi membuat partisipan perlahan-lahan bisa aktif tanpa dorongan dari pembaca cerita. Banyak partisipan yang mau berbagi cerita pengalaman pribadi yang mirip dengan cerita di buku atau partisipan menjawab pertanyaan-pertanyaan selama pembacaan buku secara tepat. Melihat keaktifan teman yang lain membuat partisipan yang lain tergerak untuk ikut aktif atau melihat teman yang lain berbagi pengalaman yang terkait dengan cerita yang ada di buku mendorong partisipan yang lain untuk ikut berbagi cerita.

Peneliti juga melakukan wawancara kepada guru untuk mengetahui perubahan perilaku anak setelah mendapatkan intervensi. Guru menyatakan bahwa sebagian besar anak menjadi kenal dengan nama-nama emosi dan hal tersebut membantu anak untuk menjaga perilaku mereka dan saling mengingatkan teman. Sebagai contoh, jika seorang anak mendorong temannya makan teman-teman yang lain akan menegur temannya dan berkata bahwa hal tersebut bisa membuat temannya sedih. Perubahan lain misalnya, ketika guru sedang menjelaskan materi dan ada teman yang berisik, teman yang lain akan mengingatkan untuk mendengarkan guru dulu agar guru mereka tidak marah. Menurut guru, intervensi yang diberikan memberikan peningkatan pemahaman anak terhadap emosi yang dirasakan oleh orang lain sehingga anak lebih memperhatikan apa yang mereka lakukan.

\section{DISKUSI}

Hasil penelitian membuktikan bahwa pembacaan cerita dengan dialogic reading efektif untuk meningkatkan pemahaman empati anak usia 3-4 tahun. Secara kuantitatif, ditemukan peningkatan skor pemahaman empati anak antara sebelum dan sesudah mengikuti program ini. Secara kualitatif, yang didaparkan dari hasil observasi dan wawancara dengan guru ditemukan adanya perubahan perilaku anak sebagai dampak dari meningkatnya pemahaman empati anak. Menurut guru, anak-anak mulai memahami apa yang dirasakan oleh orang lain sehingga mulai mempertimbangkan apa yang akan mereka lakukan. Sebagai contoh, anak mulai memahami jika mendorong teman bisa membahayakan temannya dan bisa membuat teman sedih atau anak-anak mengingatkan teman yang lain untuk mendengarkan guru bicara agar guru tidak marah. Hal ini sejalan dengan penjelasan Jalongo (2004) yang menyatakan bahwa buku cerita bergambar sesuai dengan kemampuan anak usia 3-4 tahun. Kehadiran gambar pada buku membantu anak mengidentifikasi dan mengingat cerita yang dibacakan oleh pembaca cerita, sehingga ketika dilakukan review anak dapat mengulang kembali bercerita dengan kemampuan bahasa mereka sendiri. Butler (2003 dalam Lowe, 2009) menyatakan bahwa gambar memberikan kesempatan anak untuk berkomunikasi meskipun mereka masih memiliki keterbatasan kosa kata. Hal ini juga dinyatakan oleh Alexander, Miller, dan Hengst (2010 dalam Goldberg, 2008) bahwa buku cerita bergambar mampu menjadi media anak untuk mengidentifikasi pengalaman yang dialami oleh orang lain. Kemampuan anak untuk mengidentifikasi apa yang dirasakan dan dialami orang lain membantu anak untuk mengembangkan pemahaman empatinya. 
Penelitian ini membuktikan bahwa penggunaan metode dialogic reading memberikan hasil yang signifikan untuk meningkatkan pemahaman empati anak. Hal ini terlihat dari hasil observasi yang memperlihatkan peningkatan partisipasi anak dalam pembacaan cerita. Peningkatan ini terlihat selama 4 hari pembacaan buku cerita, anak yang awalnya kesulitan untuk berpartisipasi dapat ikut berpartisipasi dalam proses pembacaan cerita. Proses meminta anak melengkapi kalimat yang dibacakan oleh pembaca cerita membantu meningkatkan kemampuan nalar anak, selain mendengarkan cerita anak juga membayangkan kejadian ini kemudian mencoba menjawab. Memberikan pertanyaanpertanyaan kepada anak membantu menjaga konsentrasi anak terhadapa kegiatan pembacaan buku cerita. Pertanyaan-pertanyaan yang mendorong anak untuk menceritakan apa yang terjadi di buku, membantu anak untuk mengingat kembali apa yang diceritakan sehingga cerita yang disampaikan dapat diterima dengan lebih baik oleh anak. Pemahaman anak terhadap cerita yang dibacakan juga dibantu oleh pertanyaanpertanyaan terbuka yang diajukan, dengan pertanyaan ini anak dibantu untuk memahami cerita secara menyeluruh. Pemahaman anak semakin terasah dengan pertanyaanpertanyaan yang mendorong anak untuk menghubungkan cerita dengan pengalaman yang pernah mereka alami. Kegiatan ini mampu membuat anak menggali pengalaman yang pernah mereka alami dan mengindetifikasikan nama emosi yang tepat untuk pengalaman mereka sehingga membantu meningkatkan pemahaman empati anak.

Pembaca cerita merupakan salah satu faktor yang mendukung metode dialogic reading dengan baik. Berdasarkan observasi yang peneliti lakukan, pembaca cerita menjadi tonggak terjadinya interaksi yang dibangun dalam metode pembacaan dialogic reading, sesuai dengan penjelasan Whitehurst (1988) bahwa orang dewasa sebagai pembaca cerita yang membentuk interaksi. Dalam proses pembacaan, pembaca cerita harus dapat mengembangkan prinsip dialogic reading untuk membangun interaksi dengan anak. Kemampuan inilah yang membantu anak untuk berpartisipasi aktif dalam pembacaan buku.

Pembacaan cerita pada penelitian ini dilakukan dalam kelompok kecil. Berdasarkan hasil observasi, pembacaan cerita dalam kelompok ini memberikan dampak positif kepada partisipan dalam kelompok. Keaktifan partisipan yang lain dalam kelompok mendorong partisipan lain yang awalnya masih malu-malu untuk berpartisipasi. Kegiatan berbagi pengalaman yang dilakukan oleh partisipan lain juga memperkaya pemahaman partisipan lain untuk memahami sebuah emosi. Hal ini sesuai dengan pernyataan Morrow dan Smith (1990) bahwa pemahaman anak lebih baik saat dilakukan pembacaan cerita dalam kelompok kecil. Selain itu perhitungan waktu yang dilakukan sejak awal pembuatan cerita melalui beberapa uji coba yang telah dilakukan juga membantu menjaga rentang konsentrasi anak. Seluruh pembacaan buku cerita yang dibacakan berdurasi antara 12-15 menit per sesi. Rentang waktu ini sesuai dengan penelitian Bloom-Hoffman (2006) yang menyatakan bahwa pembacaan buku dengan diaologic reading antara 10-15 menit untuk mempertahankan perhatian anak. Dalam rentang waktu ini pembaca cerita juga terkadang melakukan icebreaker mengenai emosi dengan bersama-sama melakukan ekspresi muka sesuai nama emosi yang disebutkan. 
Penelitian ini selain membuktikan bahwa pembacaan cerita dengan dialogic reading efektif meningkatkan pemahaman empati anak, proses pembacaan buku ini juga mengajarkan anak mengaplikasikan empati. Terjadi perubahan perilaku anak dari hari pertama pembacaan buku hingga hari terakhir. Anak yang awalnya suka menjawab sesuka hati perlahan-lahan berubah menjawab pertanyaan jika telah dipersilahkan, atau yang suka memotong teman yang sedang bercerita akan menunggu temannya selesai bercerita terlebih dahulu. Manfaat lain yang diberikan oleh pembacaan cerita dengan dialogic reading ini sesuai dengan pernyataan Doyle dan Bramwell (2006).

\section{SIMPULAN DAN IMPLIKASI}

Berdasarkan dari hasil penelitian ini membuktikan bahwa pembacaan buku cerita dengan dialogic reading efektif untuk meningkatkan pemahaman empati anak usia 3-4 tahun. Untuk penelitian selanjutnya, saran yang dapat dilakukan untuk meningkatkan pemahaman empati anak usia 3-4 tahun dengan dialogic reading, yaitu melakukan checklist perilaku anak sebelum dan sesudah mengikuti intervensi baik di sekolah atau di rumah untuk melihat perubahan perilaku anak dan program ini dapat divariasikan dengan pembacaan buku secara individual yang dapat dilakukan oleh guru atau orang tua. Selain itu melihat efektifnya dialogic reading untuk mengembangkan pemahaman empati anak, juga dapat memberikan pelatihan kepada guru mengenai metode pembacaan buku dengan dialogic reading sehingga guru dapat melakukan hal serupa dalam kegiatan belajar mengajar.

\section{REFERENSI}

Akyol, A. K. \& Durmus, A. (2012). The Development of an Empathy Scale for Children (ESC). M. Yaşar, Ö. Özgün, J. Balbraith, (Ed.), Contemporary Perspekctives and Research on Early Childhood Education, 113-123. UK: Cambridge Scholars Publishing.

Al-Somadi,M.M.F. (2012). The effect of a story - based programme on developing moral values at the kindergarten stage. Interdisciplinary journal of contemporary research in business, 4, (7). Princess Alia University College. Al-Balqa Applied University.

Arnold, D. S., \& Whitehurst, G. J. (1994). Accelerating language development through picture book reading: A summary of dialogic reading and its effect. In D. K. Dickinson (Ed.), Bridges to literacy: Children, families, and schools (pp. 103128). Malden, : Blackwell Publishing.

Blair, R. J. R. 2005. "Responding to the emotions of others: Dissociating forms of empathy through the study of typical and psychiatric populations." Consciousness and Cognition14: 698-718. https://doi.org/10.1016/j.concog.2005.06.004 
Blom-Hoffman, J., O'Neil-Pirozzi, T. M., \& Cutting, J. (2006). Read together, talk together: The acceptability of teaching parents to use dialogic reading strategies via videotaped instruction. Psychology in the Schools, 43(1), 71-78. doi:10.1002/pits.20130.

Borba, M. (2001) Building moral intelligence. US: Jossey-Bass.

Catalano, D. (2005). The roles of the visual in picturebooks: Beyond the conventions of current discourse. Ohio: The Ohio University.

Colasante, T. J. (2013). Children's moral emotions and negative emotionality: Predictors of early-onset antisocial behavior. Department of Psychology. University of Toronto. Cornell, A. H. \& Frick, P.J. (2007). The contribution of parenting styles and behavioral inhibition to the development of conscience in preschool children. Journal of Clinical Child and Adolescent Psychology, 36, 305-318.

Dadds, M. R., Hunter, K., Hawes, D. J., Frost, A. D., J., Vassallo, S., .Masry, Y. E. (2008). A measure of cognitive and affective empathy in children using parent ratings. Child Psychiatry and Human Development, 39(2), 111-22. doi:http://dx.doi.org/10.1007/s10578-007-0075-

4https://search.proquest.com/docview/1664929556? accountid=17242.

Daly, B., \& Suggs, S. (2010). Teachers' experiences with humane education and animals in the elementary classroom: Implications for empathy development. Journal of Moral Education, 39(1), 101-112. doi:10.1080/03057240903528733

Daly, B., \& Morton, L. (2006). An investigation of human-animal interactions and empathy as related to pet preference, ownership, attachment, and attitudes in children. Anthrozoos, 19, 113-127.

Decety, J., \& Moriguchi, Y. (2007). The empathic brain and its dysfunction in psychiatric populations: implications for intervention across different clinical conditions. Biopsychosocial Medicine, 1, (22).

DeTemple, J., \& Snow, C. E. (2003). Learning words from books. In S. Stahl, A. van Kleeck \& E. B. Bauer (Eds.), On reading books to children: Parents and teachers (pp. 16-36). Mahwah, NJ: Erlbaum.

Doyle, B. G. and Bramwell, W. (2006), Promoting Emergent Literacy and Social Emotional Learning Through Dialogic Reading. The Reading Teacher, 59: 554564. doi:10.1598/RT.59.6.5.

Eidsvaag, L. I. (2012). Empathy in two-year-olds: A naturalistic study of toddler social understanding (Order No. 1520479). Available from ProQuest Dissertations \& Theses Global: The Humanities and Social Sciences Collection. (1095720657). Retrieved from https://search.proquest.com/docview/1095720657?accountid=25704 
Eisenberg, N., Fabes, R. A., \& Spinrad, T. L. (2006). Prosocial development. In N. Eisenberg, W. Damon, \& R. M. Lerner (Eds.), Handbook of Child Psychology: Vol. 3, Social, Emotional, and Personality Development (6th ed., pp. 646-718). Hoboken, NJ: Wiley.

Ewers, C., \& Brownson, S. (1999). Kindergarteners' Vocabulary Acquisition As a Function of Active Vs. Passive Storybook Reading, Prior Vocabulary, and Working Memory. Reading Psychology, 20 (1), 11-20. doi:10.1080/027027199278484.

Flynn, K. S. (2011). Developing children's oral language skills through dialogic reading: Guidelines for implementation. Teaching Exceptional Children, 44(2), 8-16. doi:10.1177/004005991104400201.

Goldberg, J. (2008). Helping young children understand a mother's bipolar disorder: A children's book. Clinical dissertation. CA: The California School of Professional Psychology Alliant International University.

Goleman, D. (2005). Emotional Intelligence: Why It Can Matter More Than IQ. New York: Bantam Book.

Gordon, M. (2009). Roots of Empathy: Changing the World Child by Child. New York: The Experiment.

Gravetter, F. J., \& Forzano, L.-A. B. (2009). Research methods for the behavioral sciences. Belmont, CA: Wadsworth Cenage Learning.

Hinnant, J. B. (2005). Cognitive and emotional constructs and their relation to empathy in young children (Order No. 1431890). Available from ProQuest Dissertations \& Theses Global. (305424413). Retrieved from http://search.proquest.com/docview/305424413?accountid=17242.

Hoffman, M. L. (2000). Empathy and moral development: Implications forcaring and justice. Cambridge, England: Cambridge University Press.

Howe, A., Pit-ten Cate, I. M., Brown, A., \& Hadwin, J. A. (2008). Empathy in preschool children: The development of the southampton test of empathy for preschoolers (STEP). Psychological Assessment, 20(3), 305-309. doi:http://dx.doi.org/10.1037/a0012763.

Işıtan, S. (2016). Illustrated Storybooks for Preschool Children Published in Turkey Between 1980-2013: A Study Based on Preschool Education Reforms. Educational Sciences: Theory \& Practice, 16(2), 669-690. doi:10.12738/estp.2016.2.2862

Jalongo, M. R. (2004). Young children and picture books (2nd. ed). Washington: National Association for the Education of Young Children.

Jefferies, A. M. (2005). Teaching empathy to children in grades five through seven: An evaluation of the primary prevention program (Order No. 1429954). Available 
from ProQuest Dissertations \& Theses Global. (305002580). Retrieved from http://search.proquest.com/docview/305002580?accountid=17242

Karniol, R. (2012). Storybook-Induced Arousal and Preschoolers' Empathic Understanding of Negative Affect in Self, Others, and Animals in Stories. Journal Of Research In Childhood Education, 26(3), 346-358. doi:10.1080/02568543.2012.684423.

Knafo, A., Zahn-Waxler, C., Van Hulle, C., Robinson, J. L., \& Rhee, S. H. (2008). The developmental origins of a disposition toward empathy: Genetic and environmental contributions. Emotion, 8(6), 737-752. doi:http://dx.doi.org/10.1037/a0014179.

Knafo, A., \& Plomin, R. (2006). Parental discipline and affection and children's prosocial behavior: Genetic and environmental links. Journal of Personality and Social Psychology, 90(1), 147-164. http://dx.doi.org/10.1037/0022-3514.90.1.147

Kumar, R. (2011). Research methodology: A step-by-step guide for beginners. Los Angeles: SAGE.

Lane, H. B. and Wright, T. L. (2007), Maximizing the Effectiveness of Reading a loud. The Reading Teacher, 60: 668-675. doi:10.1598/RT.60.7.7

Liputan 6: http://news.liputan6.com/read/2154228/komnas-pa-prediksi-pelakukekerasananak-meningkat-18-tahun-2015

Losoya, S. H., \& Eisenberg, N. (2001). Affective Empathy. In Hall, J. A. \& Bernieri, F. J. (Eds), Interpersonal Sensitivity Theory and Measurement (pp. 21-43). Mahwah, NJ: Lawrence Erlbaum Associates Publishers.

Lowe, D. F. (2009). Helping children cope through literature. Forum on Public Policy Online, 2009(1), 1-17.

Malti, T., \& Krettenauer, T. (2013). The Relation of Moral Emotion Attributions to Prosocial and Antisocial Behavior: A Meta-Analysis. Child Development, 84(2), 397-412. doi:10.1111/j.1467-8624.2012.01851.x

Maughan, B., Rowe, R., Messer, J., Goodman, R. and Meltzer, H. (2004). Conduct Disorder and Oppositional Defiant Disorder in a national sample: developmental epidemiology. Journal of Child Psychology and Psychiatry, 45: 609-621. doi:10.1111/j.1469-7610.2004.00250.x

McDonald, N. M., \& Messinger, D. S. (2011). The development of empathy: How, when, and why. Moral Behavior and Free Will: A Neurobiological and Philosophical Aprroach, 341-368.

McInnis, M. A. (2014). The relation between theory of mind and empathy in preschool: The case of fantasy orientation (Order No. 3639170). Available from ProQuest Dissertations \& Theses Global: The Humanities and Social Sciences Collection. 
(1620540550).

Retrieved

from https://search.proquest.com/docview/1620540550?accountid=25704

Mol, S. E., Bus, A. G., de Jong, M. T., \& Smeets, D. J. H. (2008). Added value of dialogic parent-child book readings: A meta-analysis. Early Education \& Development, 19(1), 7-26. doi:10.1080/10409280701838603.

Narvaez, D. (2002). Does reading moral stories build character? Educational Psychology Review, 14(2), 155-171. doi:10.1023/A:1014674621501.

Papalia, D.E. \& Martorell, G., (2014).Experience human development (13th Edition). NY: McGraw-Hill Education.

Pillinger, C., \& Wood, C. (2014). Pilot study evaluating the impact of dialogic reading and shared reading at transition to primary school: Early literacy skills and parental attitudes: Dialogic reading and early literacy. Literacy, 48(3), 155-163. doi:10.1111/lit.12018

Prianto, R. M. (2006). Pengaruh empati, hati nurani, dan perkembangan moral ibu terhadap perkembangan moral anak melalui gaya pengasuahan ibu. Fakultas Psikologi: Universitas Indonesia.

Roth-Hanania, R., Davidov, M., \& Zahn-Waxler, C. (2011). Empathy development from 8 to 16 months: Early signs of concern for others. Infant Behavior \& Development, 34, 447-458. doi:10.1016/j.infbeh .2011.04.007.

Shanty, L. M. (2016). Preschool children's emotion knowledge: Storybooks as a learning tool (Order No. 10140618). Available from ProQuest Dissertations \& Theses Global. (1806117267). Retrieved from http://search.proquest.com/docview/1806117267?accountid=17242

Stetson, E. A., Hurley, A. M., \& Miller, G. E. (2003). Can universal affective education programs be used to promote empathy in elementary aged children? A review of five curricula. Journal of Research in Character Education, 1(2), 129-147. Retrieved from http://search.proquest.com/docview/231714157?accountid=17242

Tempo: https://m.tempo.co/read/news/2014/12/31/174632007/sepanjang-2014kejahatanterhadap-anak-meningkat

Thompson, K. L. \& Gullone, E. (2003), Promotion of Empathy and Prosocial Behaviour in Children Through Humane Education. Australian Psychologist, 38: 175-182. doi:10.1080/00050060310001707187

Upright, R. L. (2002). To tell a tale: The use of moral dilemmas to increase empathy in the elementary school child. Early Childhood Education Journal, 30(1), 15-20. doi:http://dx.doi.org/10.1023/A:1016585713774

Venesky, L. G. (2013). An exploration of the development of empathy in a clinical sample of preschoolers in relation to child and family factors (Order No. 3557572). Available from ProQuest Dissertations \& Theses Global. 
(1346230991).

Retrieved

from http://search.proquest.com/docview/1346230991?accountid=17242

Volbrecht, M. M., Lemery-Chalfant, K., Aksan, N., Zahn-Waxier, C, \& Hill Goldsmith, H. (2007). Examining the familial link between positive affect and empathy development in the second year. Journal of Genetic Psychology, 168(2), 105-129.

Vreeke, G. J., \& van der Mark, I. L. (2003). Empathy, an integrative model. New Ideas in Psychology, $21(3)$, 177-207. http://dx.doi.org/10.1016/j.newideapsych.2003.09.003

Wang, Hui-Hua, "Home Literacy Environment, the Quality of Mother-Child Book Reading Interactions, and Taiwanese Children's Early Literacy Development" (2014).Dissertations - ALL Paper 198.

Widyana, S. P. (2012). Efektivitas pembacaan buku cerita pada program perkembangan kemampuan empati anak usia 6-7 tahun. Universitas Indonesia: Fakultas Psikologi.

Xerri, D., \& Agius, S. X. (2015). Galvanizing empathy through poetry. English Journal, 104(4), 71-76.

Zembylas, M. (2013). The Emotional Complexities of "Our" and "Their" Loss: The Vicissitudes of Teaching about/for Empathy in a Conflicting Society. Anthropology \& Education Quarterly, 44(1), 19-37. doi:10.1111/j.15481492.2012.01175.x 